
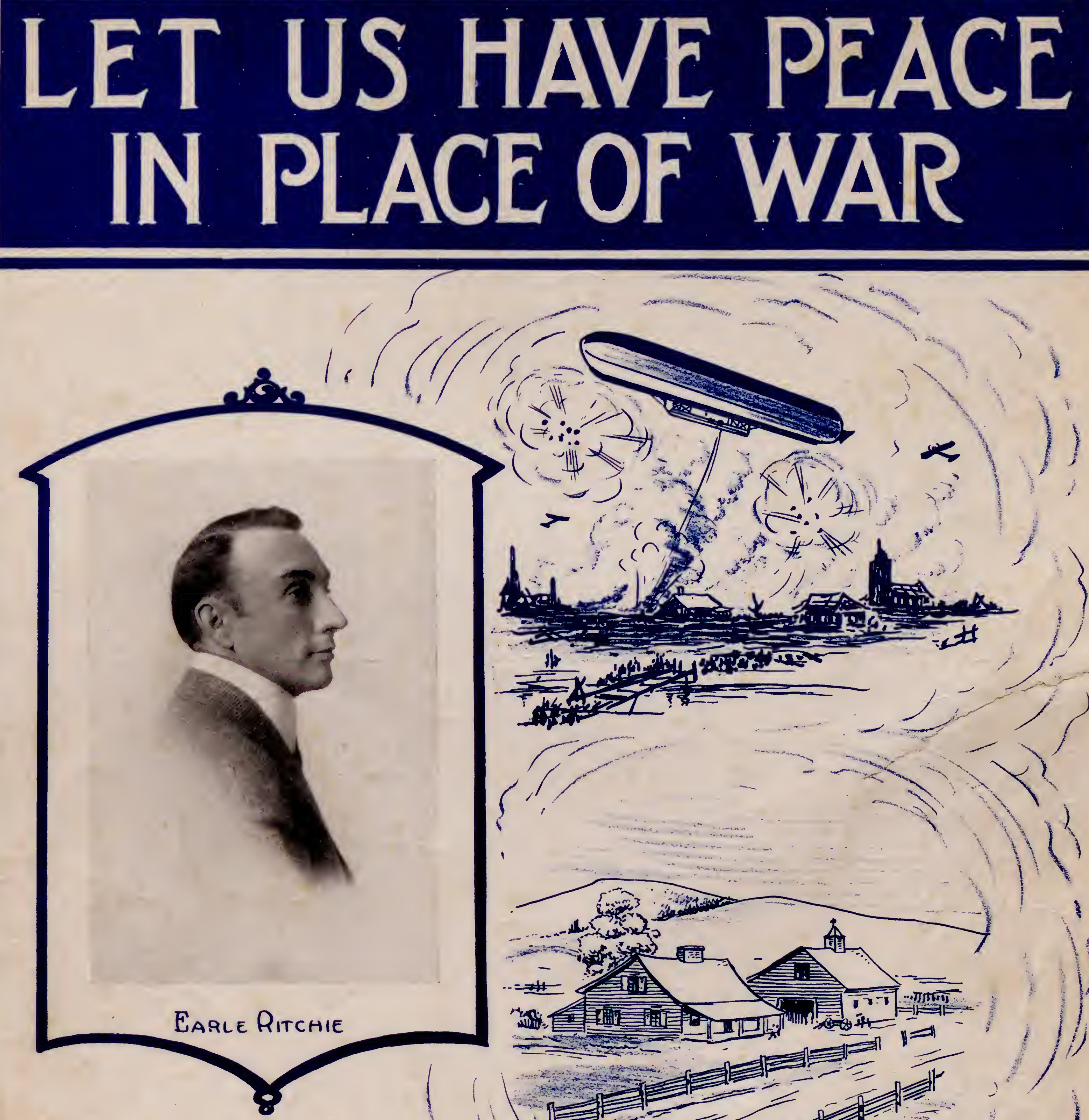

WORDS E MUSIC EY

Earle Ritchie
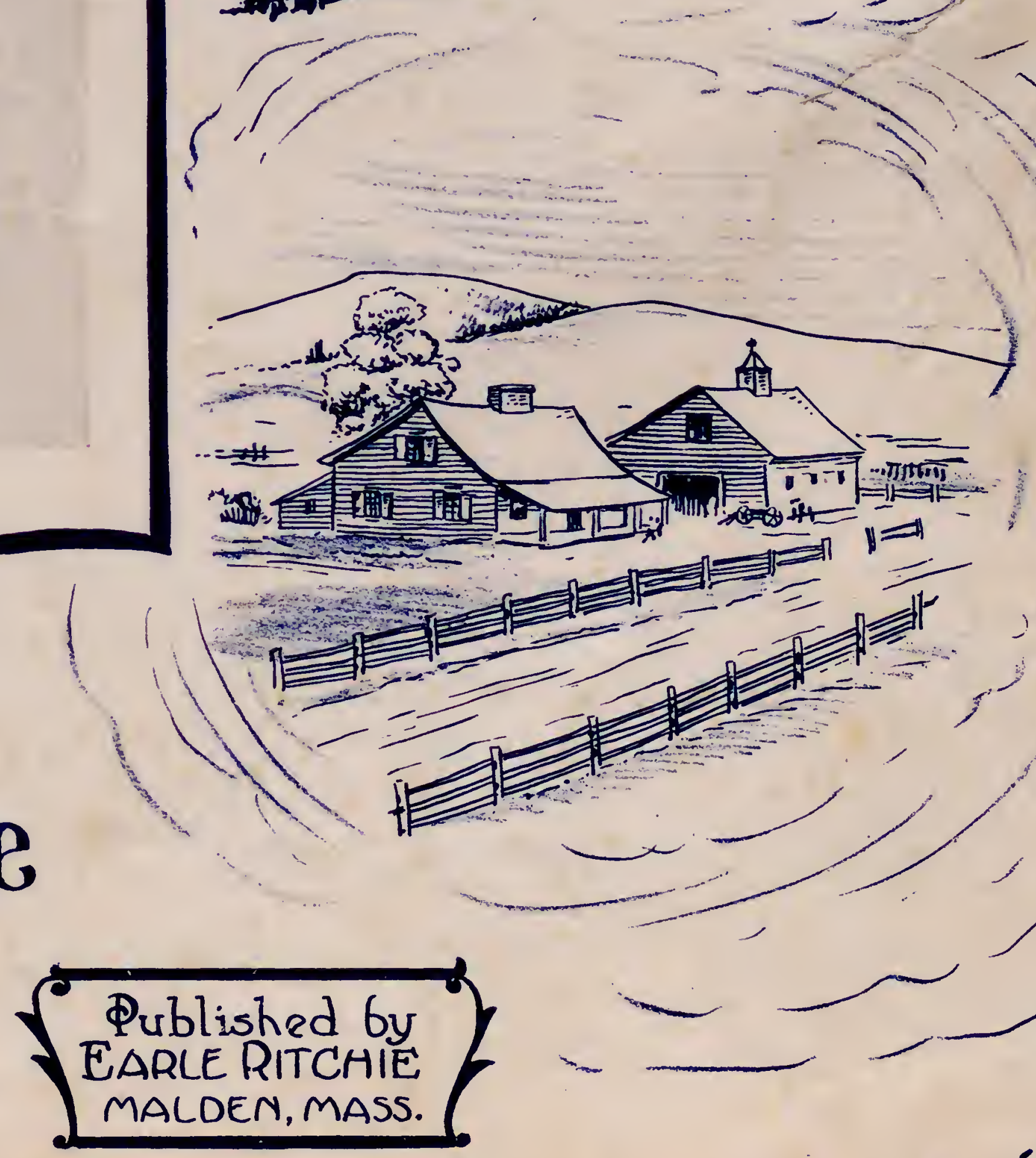
It 10 s $\frac{1}{5} \times 1$
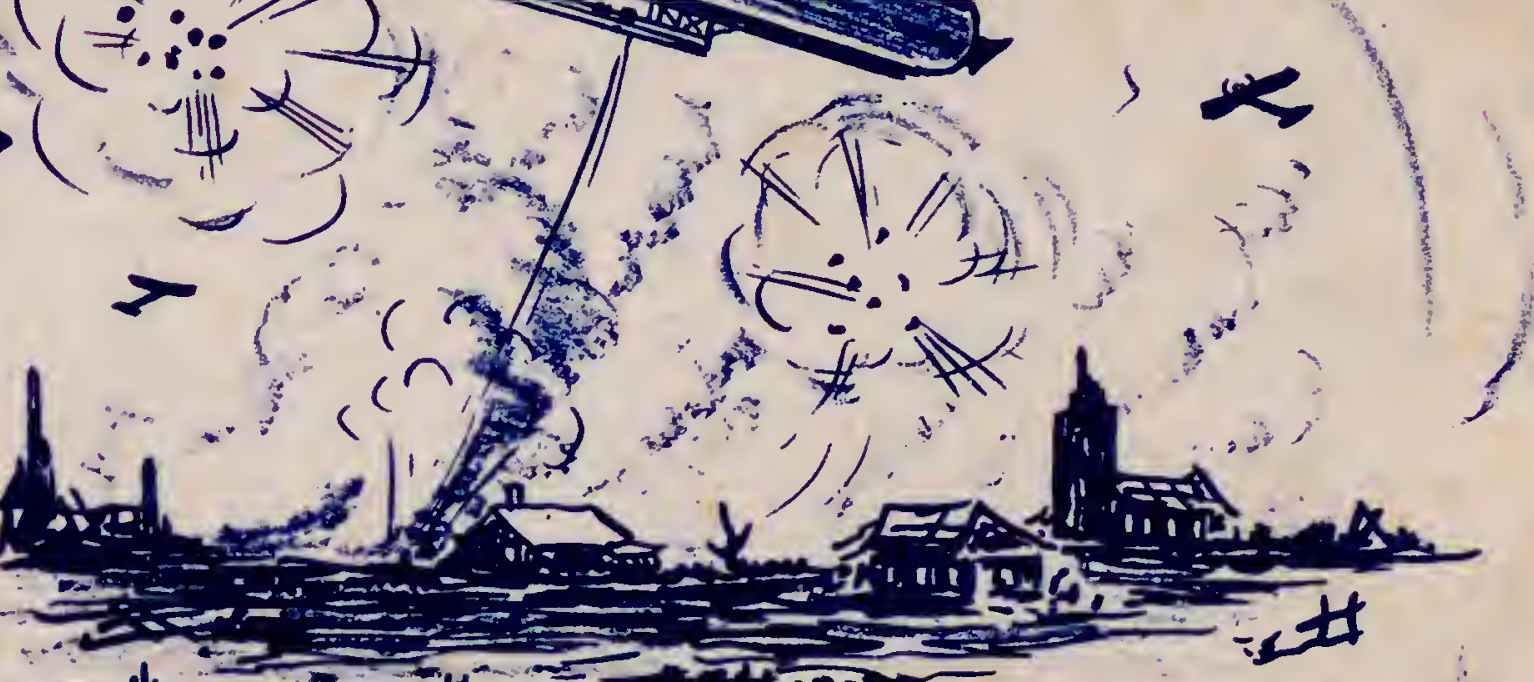



\title{
LET US HAVE PEACE IN PLACE OF WAR
}

\author{
(MARCH SONG)
}

Words and Music by

Tempo di Marcia

EARLE RITCHIE

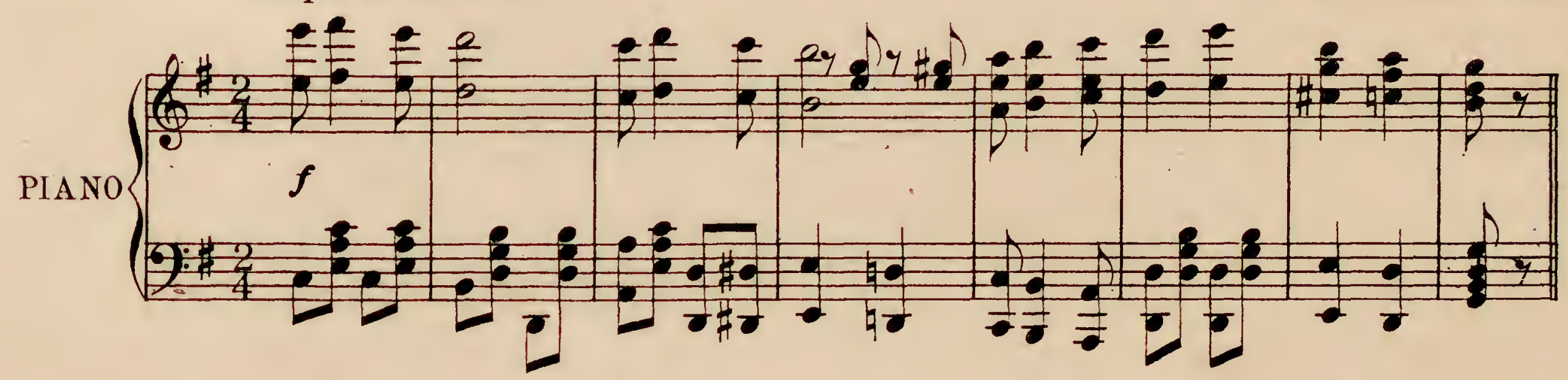

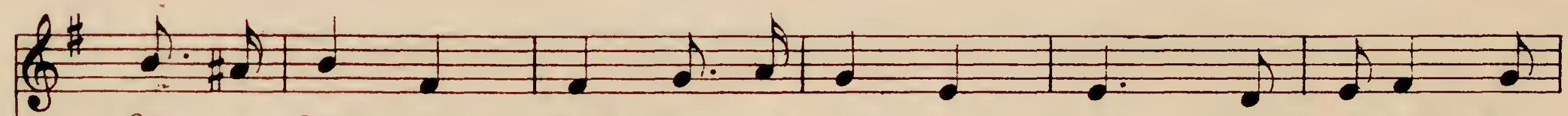

On a bat - tle - field lies a sold - ier boy who fought for his
in a far off land there a moth - er waits for her on - ly
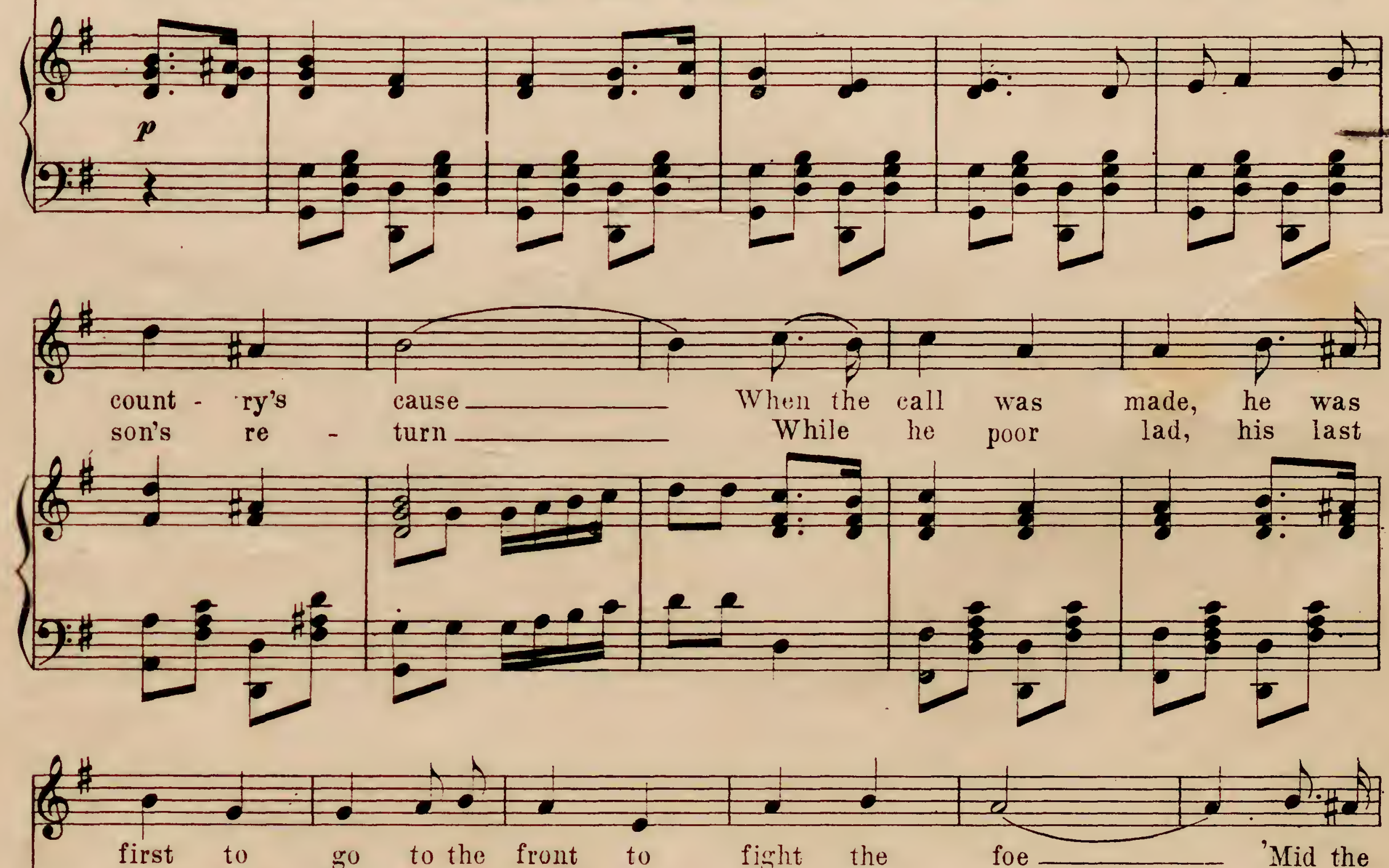
look has had onthat face he loved so well_ He is

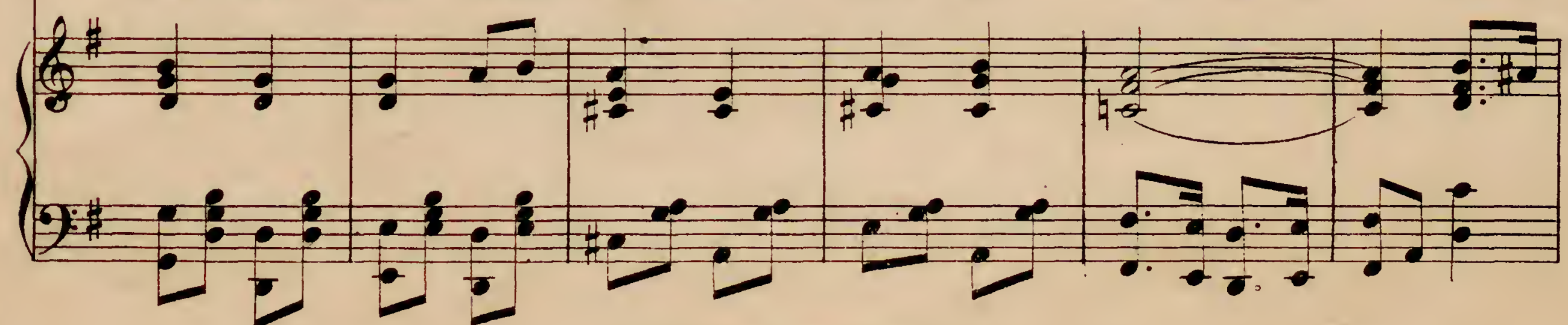

Copyright, 1915 , by Earle Ritchie 
4
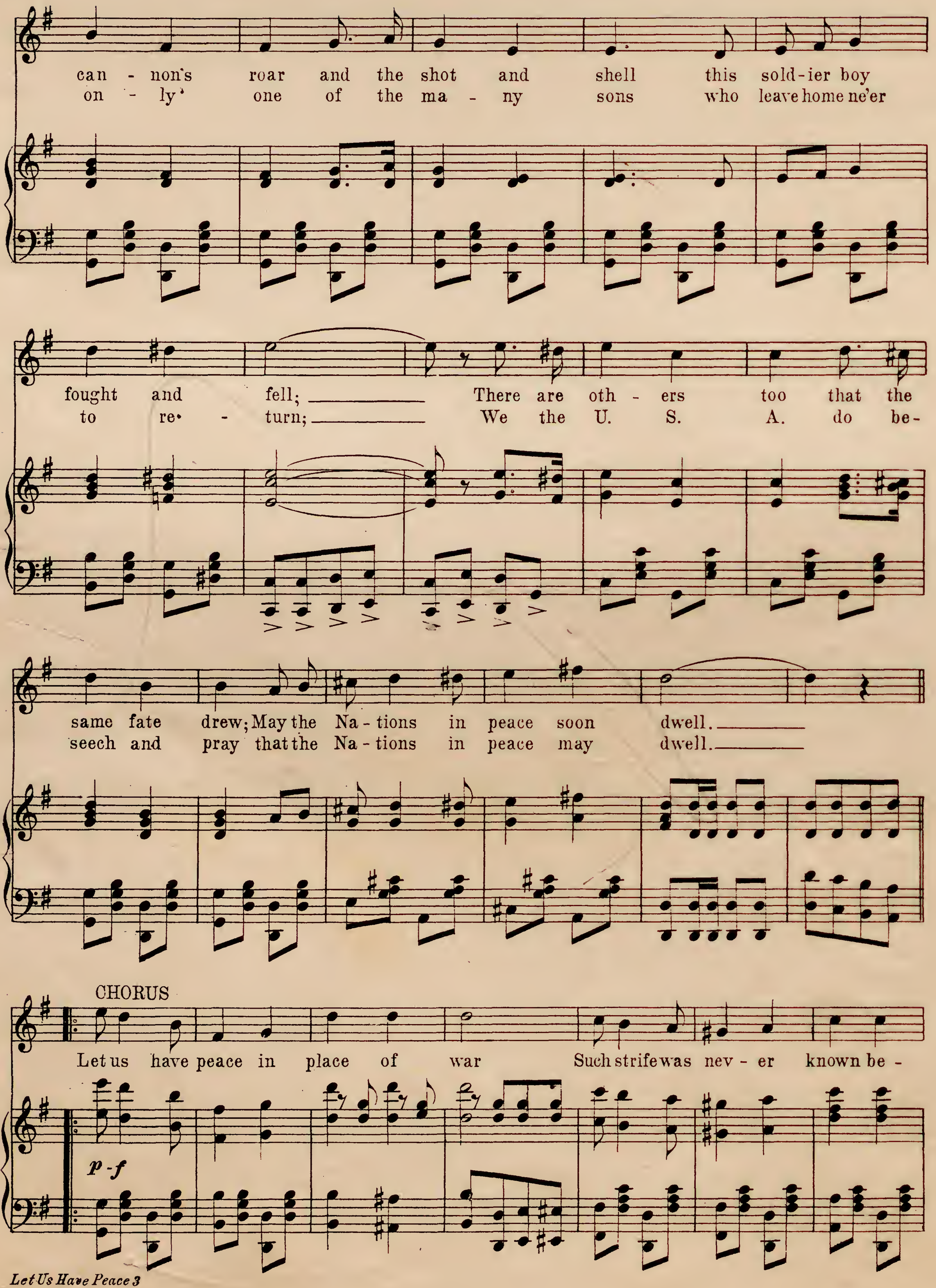

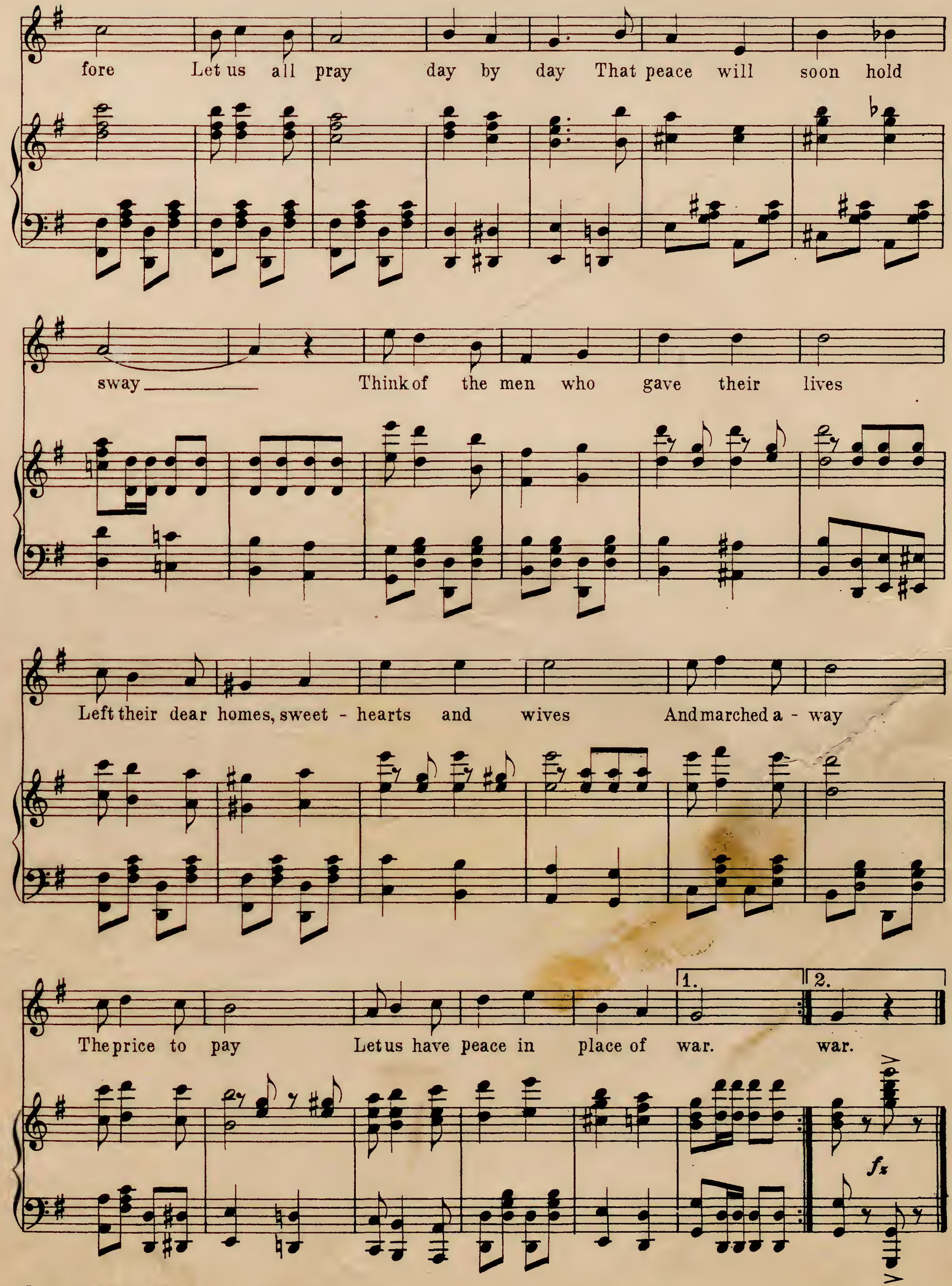

Let Us Have Peacs 3 
